\title{
Series Resistance Analysis of Passivated Emitter Rear Contact Cells Patterned Using Inkjet Printing
}

\author{
Martha A. T. Lenio, ${ }^{1}$ James Howard, ${ }^{1}$ Doris (Pei Hsuan) Lu, ${ }^{1}$ Fabian Jentschke, ${ }^{2}$ \\ Yael Augarten, ${ }^{1}$ Alison Lennon, ${ }^{1}$ and Stuart R. Wenham ${ }^{1}$ \\ ${ }^{1}$ Electrical Engineering Department, School of Photovoltaic and Renewable Energy Engineering, \\ University of New South Wales, Sydney, NSW 2052, Australia \\ ${ }^{2}$ Energy Australia, Sydney, NSW 2001, Australia
}

Correspondence should be addressed to Martha A. T. Lenio, m.lenio@student.unsw.edu.au

Received 1 March 2012; Revised 4 August 2012; Accepted 22 August 2012

Academic Editor: Fengqiang Sun

Copyright ( $) 2012$ Martha A. T. Lenio et al. This is an open access article distributed under the Creative Commons Attribution License, which permits unrestricted use, distribution, and reproduction in any medium, provided the original work is properly cited.

\begin{abstract}
For higher-efficiency solar cell structures, such as the Passivated Emitter Rear Contact (PERC) cells, to be fabricated in a manufacturing environment, potentially low-cost techniques such as inkjet printing and metal plating are desirable. A common problem that is experienced when fabricating PERC cells is low fill factors due to high series resistance. This paper identifies and attempts to quantify sources of series resistance in inkjet-patterned PERC cells that employ electroless or light-induced nickelplating techniques followed by copper light-induced plating. Photoluminescence imaging is used to determine locations of series resistance losses in these inkjet-patterned and plated PERC cells.
\end{abstract}

\section{Introduction}

As the photovoltaics industry becomes more mature, manufacturers must find new ways of staying competitive. Developing cost-effective ways of fabricating higher-efficiency cell structures that have to date only been realized in a laboratory environment is an option that is being considered by many. An obvious cell structure to attempt to commercialise is the Passivated Emitter Rear Contact (PERC) cell $[1,2]$.

New patterning methods such as inkjet printing and laser doping [3-5] enable the patterning of dielectric layers for metal contacting and therefore eliminate the need to use techniques such as photolithography which enabled the earlier laboratory implementations of these cells. Metal plating, which has been successfully used for the manufacture of photovoltaic devices in industry [6], is compatible with these patterning methods and consequently presents as a commercially viable metallization method. In addition to enabling the use of less expensive metals like $\mathrm{Ni}$ and $\mathrm{Cu}$, metal plating is a self-aligning process thus eliminating the need for the photolithographic lift-off steps which were used in conjunction with evaporated Ti-Pd-Ag metal contacts. A further advance that is desirable to make PERC cells commercially viable is to reduce the number of high temperature steps $[7,8]$.

This paper contains an analysis of the series resistance losses of PERC cells that have been fabricated using inkjet printing (IJP) for the patterning steps and self-aligned $\mathrm{Ni}$ and $\mathrm{Cu}$ plating for the metallization. The fabricated PERC cells were analyzed using photoluminescence (PL) imaging, current-voltage (IV) measurements, and microscopy. Transmission line model (TLM) test structures were fabricated to characterize the metal-silicon interface and estimate the contact resistance associated with both the front and rear metal contacts. The findings of this work show that a decrease in fill factor due to high series resistive losses is a problem with electrolessly plated PERC cells. This is consistent with the findings of other researchers who have seen fill factor losses in their electrolessly plated PERC cells that were formed using laser-fired rear contacts [9]. It was found here that spurious $\mathrm{Ni}$ plating on the rear point contacts forms during electroless $\mathrm{Ni}$ plating, and this contributes 
significantly to the high series resistance and resulting low fill factors of final devices. Poorly adhered front contacts were also an issue with inkjet-printed and electrolessly plated PERC cells. It is shown that use of appropriate plating techniques, such as bias-assisted light induced plating, can help reduce these resistive effects.

\section{Experimental Procedure}

2.1. Cell and Test Structure Fabrication. Cells and test structures were fabricated on planar, $0.5 \Omega \cdot \mathrm{cm}$, p-type, $200 \mu \mathrm{m}$ thick, FZ Si wafers. The processing sequence used for the cells is outlined in Table 1. The emitter sheet resistance after processing was $\sim 120 \Omega / \square$. Nickel contacts were formed using both electroless plating and bias-assisted LIP. In the latter process, a bias voltage of $0.6 \mathrm{~V}$ was applied to the rear $\mathrm{Al}$ surface of the devices (this setup can be seen in Figure 1(a)). All $\mathrm{Cu}$ plating was performed using noncontact LIP without an applied bias (see Figure 1(b)).

The dimensions of the completed cells are detailed in Table 2. The TLM test structures underwent the same thermal processing as the fabricated cells. The only difference in the fabrication sequence was the inkjet patterning. Instead of forming openings for front finger grids and rear point contacts, TLM contact pads were patterned using the indirect inkjet patterning method [5] for the (front) $\mathrm{Ni}$ and (rear) $\mathrm{Al}$ contact resistance test structures. For the rear measurements, TLM contact pads of $\mathrm{Al}$ were evaporated through a mask which was aligned to the inkjet-patterned openings in the rear $\mathrm{SiO}_{2}$ dielectric layer.

2.2. Analysis. The series resistance of the final IJP PERC cells was estimated from comparing the light-IV measurements with the Suns- $V_{\text {oc }}$ measurements [10]. Photoluminescence (PL) imaging was used to record a spatially resolved image of the voltage across the cells. Two types of PL imaging were used: open-circuit PL and $R_{s}-\mathrm{PL}[11,12]$. The contributing components of the series resistance were identified, and each component was calculated using actual dimensions and resistances measured from test structures. Scanning electron microscope (SEM), focused ion beam (FIB), and optical microscopy were used to inspect the quality of the metal contacts and to help determine the underlying causes of the high series resistance problems experienced by IJP PERC cells.

\section{Results and Discussion}

3.1. Contact Resistance Results. The TLM measurements for the front $\mathrm{Ni}$ contacts depended on the plating technique used, with the average specific contact resistivity being $0.07 \pm$ $0.04 \Omega \cdot \mathrm{cm}^{2}$ and $0.09 \pm 0.02 \Omega \cdot \mathrm{cm}^{2}$ for electroless $\mathrm{Ni}$ and bias-assisted LIP Ni contacts, respectively. There were some variations between individual test structures using the same $\mathrm{Ni}$-plating technique, particularly with the electroless $\mathrm{Ni}$ plated cells. Specific contact resistivities as low as $3.5 \times$ $10^{-5} \Omega \cdot \mathrm{cm}^{2}$ have been reported previously for $\mathrm{Ni} / \mathrm{Cu}$-plated fingers [19]. The discrepancy between the resistivity values could be due to the difficulty experienced in achieving good adhesion between the $\mathrm{Ni}$ and $\mathrm{Si}$.

The specific contact resistivity for the Al-Si rear contact TLM test structures was measured to be $0.004 \pm 0.003 \Omega \cdot \mathrm{cm}^{2}$ and $0.028 \pm 0.010 \Omega \cdot \mathrm{cm}^{2}$, before and after electroless $\mathrm{Ni}$ plating, respectively. The value before electroless $\mathrm{Ni}$ plating is higher but on the same order of magnitude as previously reported values of $0.0015 \Omega \cdot \mathrm{cm}^{2}$ for $\mathrm{Al}$ on $0.5 \Omega \cdot \mathrm{cm}$ p-type Si $[18,20,21]$. The increase in specific contact resistivity after electroless plating was due to spurious Ni plating at the Al-Si rear contacts [18]. Figure 2 shows an FIB image of $\mathrm{Ni}$ plated around a rear point contact on an IJP PERC cell that underwent electroless Ni plating. Nickel plates preferentially on the rear surface at regions where the $\mathrm{Al}$ is rough or contains a higher Si content than the surrounding Al [18]. In some areas, the $\mathrm{Ni}$ displaces the $\mathrm{Al}$ through galvanic displacement, coming into direct contact with the Si (see Figure 3). This plated $\mathrm{Ni}$ contributes to the metal Si contact and causes increased contact resistance due to the fact that $\mathrm{Ni}$ has a higher barrier height on p-type Si than $\mathrm{Al}$ [20].

The spurious rear-side Ni plating was only observed with cells and test structures which underwent electroless $\mathrm{Ni}$ plating. In bias-assisted LIP, the rear surface was protected from undesired plating by the bias voltage, and so rear-side plating was avoided. The absence of $\mathrm{Ni}$ on the rear contacts means that the Al-Si contact resistance measured from the test TLMs can be used as the contact resistance for rear contacts formed using BA-LIP.

3.2. Light IV Results. The cells were tested under standard conditions using an Adventest DC Voltage Current Source/Monitor, a temperature-controlled copper block, and a halogen lamp light source calibrated to one-sun using a calibrated reference cell. Suns- $V_{\text {oc }}$ measurements were done using a flash tester, and the series resistance was estimated from comparing the light IV data to the Suns- $V_{\text {oc }}$ data. The open-circuit voltage $\left(V_{\mathrm{oc}}\right)$, fill factor $(\mathrm{FF})$, series resistance $\left(R_{s}\right)$, and shunt resistance $\left(R_{\mathrm{sh}}\right)$ data for the cells plated using electroless Ni and BA-LIP Ni are listed in Table 3. The series resistance of the electroless Ni-plated cell was higher than that measured in the BA-LIP Ni-plated cell. The FFs of both cells are remarkably low. Shunting was an issue particularly for the BA-LIP sample, and the series resistance was high for both cells. The shunting in the BA-LIP batch of samples was due to inadequate resist coating on the front surface of the cell during the rear contact patterning step. Pinholes formed, creating holes through the dielectric and emitter which were subsequently plated with metal.

3.3. Photoluminescence Results. Photoluminescence imaging gives a spatially resolved image of locations of high and low voltages within a cell or wafer. When the cell is at open circuit, there is no lateral current flow, so areas of low voltage represent areas of high recombination. The PL intensity is directly proportional to the exponential of the voltage according to (1) [22]:

$$
I_{\mathrm{PL}, i}=C_{i} \exp \left(\frac{e U_{i}}{k T}\right),
$$




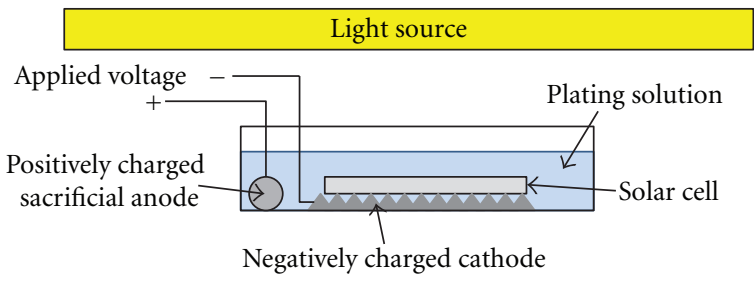

(a)

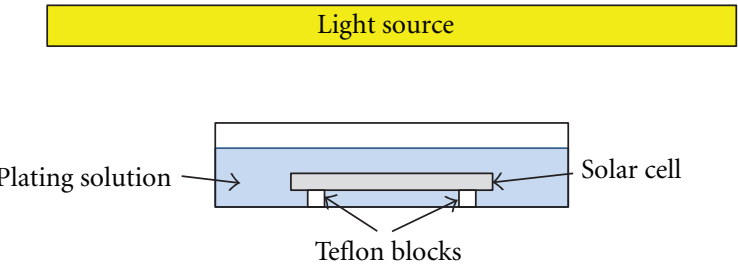

(b)

Figure 1: Experimental setup for (a) bias-assisted LIP; (b) noncontact LIP.

TABLE 1: Processing sequence for IJP PERC cells.

\begin{tabular}{|c|c|c|}
\hline Step & Process & Conditions \\
\hline (1) & Damage etch/texture & 20 min etch in $30 \% \mathrm{NaOH}$ at $80^{\circ} \mathrm{C}$ \\
\hline (2) & Oxidation & Dry oxidation, $1030^{\circ} \mathrm{C}$ for $4 \mathrm{hr}$ with $1 \%$ TCA in $\mathrm{O}_{2}$ \\
\hline (3) & Strip front oxide & Mask rear; strip $\mathrm{SiO}_{2}$ with buffered $\mathrm{HF}$ \\
\hline (4) & Emitter diffusion + oxidation & $\begin{array}{l}\text { Diffusion: P solid source, } 850^{\circ} \mathrm{C}, 15 \mathrm{~min} \\
\text { Oxidation: } 1100^{\circ} \mathrm{C}, 5 \mathrm{hr}, 1 \% \mathrm{TCA} \text { in } \mathrm{O}_{2}, 15 \mathrm{~min} \text { anneal in } \mathrm{N}_{2}\end{array}$ \\
\hline (5) & IJP the front contacts & Indirect IJP method [5] \\
\hline (6) & Groove diffusion + drive-in & $\begin{array}{l}\text { Diffusion: } \mathrm{P} \text { solid source, } 940^{\circ} \mathrm{C}, 90 \mathrm{~min} \\
\text { Drive-in: } 1000^{\circ} \mathrm{C}, 3 \mathrm{hr}, \mathrm{N}_{2}\end{array}$ \\
\hline (7) & IJP the rear contacts & Indirect IJP method [5] \\
\hline (8) & Evaporate rear $\mathrm{Al}+$ sinter & $1-2 \mu \mathrm{m} \mathrm{Al}$, sinter at $400^{\circ} \mathrm{C}, 30 \mathrm{~min}$ in forming gas \\
\hline (9) & Ni plate + anneal & Various plating methods; anneal at $400^{\circ} \mathrm{C}, 10 \mathrm{~min}$ in forming gas \\
\hline$(10)$ & $\mathrm{Cu}$ light-induced plate & $\mathrm{Cu}$ electroplating solution, 5 min under high-intensity fluorescent light \\
\hline$(11)$ & Edge isolation & Cut with a $1064 \mathrm{~nm}$ Nd: YAG laser from the rear; cut $1 / 2$ way thru wafer then snapped \\
\hline
\end{tabular}

Ni plating was done in one of two ways: (i) electroless Ni using Transene EN solution [9], $80^{\circ} \mathrm{C}$ for 3 min; or (ii) BA-LIP Ni, 25-30 $\mathrm{C}$ for $30 \mathrm{~s}$ under highintensity fluorescent light. The BA-LIP Ni consisted of Watt's solution in the ratios $10 \mathrm{~g} \mathrm{Ni}_{2} \mathrm{SO}_{4}, 20 \mathrm{~g} \mathrm{NiCl}_{2}, 4 \mathrm{~g}$ boric acid in $100 \mathrm{~mL}$ deionized water [13]. The electroplating solution for the Cu plating used $12 \mathrm{~g} \mathrm{CuSO}_{4}, 11 \mathrm{~mL} \mathrm{H}_{2} \mathrm{SO}_{4}$, and $50 \mathrm{~mL}$ deionized water.

TABLE 2: Dimensions for cell design and analysis.

\begin{tabular}{lcc}
\hline Parameter & Value & Variability \\
\hline Cell area & $8 \mathrm{~cm}^{2}$ & $\pm 0.15 \mathrm{~cm}^{2}$ \\
Finger width & $90 \mu \mathrm{m}$ & $\pm 10 \mu \mathrm{m}$ \\
Finger height & $5 \mu \mathrm{m}$ & $\pm 2 \mu \mathrm{m}$ \\
Finger length & $28 \mathrm{~mm}$ & $\pm 0.5 \mathrm{~mm}$ \\
Finger spacing & $1.2 \mathrm{~mm}$ & $\pm 10 \mu \mathrm{m}$ \\
Rear contact diameter & $100 \mu \mathrm{m}$ & $\pm 10 \mu \mathrm{m}$ \\
Rear contact spacing & $1.5 \mathrm{~mm}$ & $\pm 10 \mu \mathrm{m}$ \\
\hline
\end{tabular}

where $I_{\mathrm{PL}, i}$ is the PL intensity at a specific location $i, U_{i}$ is the voltage at that location, and $C_{i}$ is a local calibration constant. With an open circuit PL image, the calibration constant can be calculated using the $V_{\text {oc }}$ obtained from the light IV measurement along with the average PL signal from the PL image [22]. This then allows the voltage at any particular point in the image to be calculated from the PL signal.

Figure 4(a) shows an open-circuit PL image of an inkjetpatterned PERC cell that had its front metal contacts formed using electroless Ni plating followed by LIP Cu plating. The rear point contacts can be clearly seen in this image. At open circuit, with no current extraction occurring, locations of

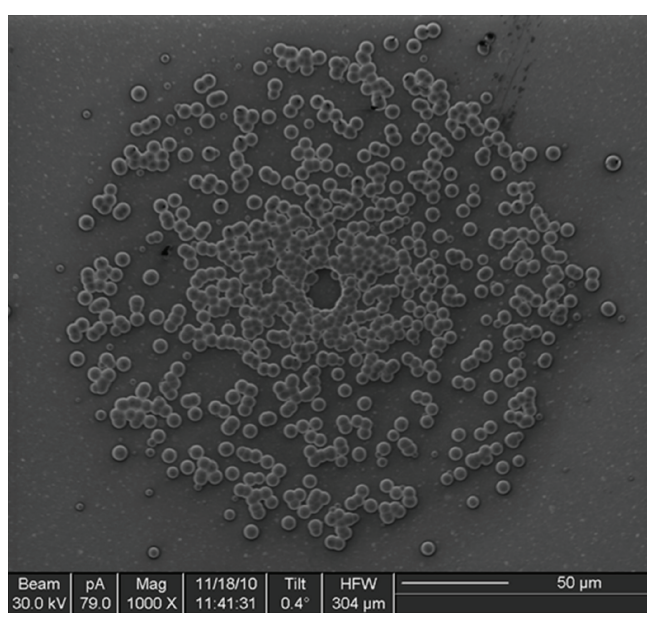

Figure 2: Focused ion beam (FIB) image of the rear of a test cell. Unwanted Ni plating can be seen around a rear point contact on an IJP PERC cell plated using electroless Ni [18].

low voltage must be due to either shunts or high recombination (low lifetime). Some shunts are apparent, as larger dark spots in a few locations on the wafer, but the regular 
TABLE 3: Cell performance from light IV data.

\begin{tabular}{lcccc}
\hline Ni-plating method & $V_{\text {oc }}(\mathrm{mV})$ & Fill factor & Series resistance $\left(\Omega \cdot \mathrm{cm}^{2}\right)$ & Shunt resistance $\left(\mathrm{k} \Omega \cdot \mathrm{cm}^{2}\right)$ \\
\hline Electroless Ni & 646 & 0.61 & 4.1 & 42.7 \\
Bias-assisted LIP Ni & 617 & 0.59 & 1.5 & 0.10 \\
\hline
\end{tabular}

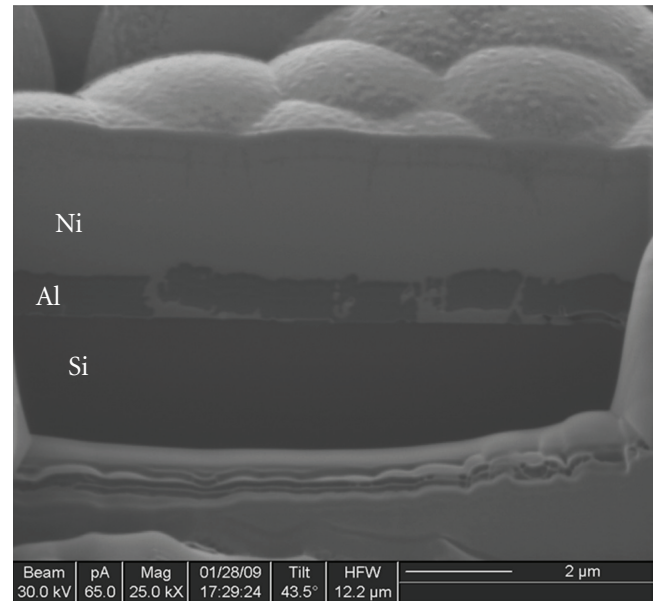

FIGURE 3: Focused ion beam (FIB) cross-section image of the rear contact of a test cell. Unwanted electroless $\mathrm{Ni}$ plating at the rear point contact has displaced some of the $\mathrm{Al}$, contacting the Si surface and increasing the contact resistance [18].

rear contact design is also seen as a regular, shadowy pattern across the entire wafer. These contact locations are necessarily identified as locations of high recombination as a result.

Figure 4(b) shows the series resistance PL image of an electroless Ni-plated cell. In this image, bright areas indicate regions of high series resistance. Prominent features are the bright areas on the left and right edges of the cell, as well as the two darker regions spreading out from the busbar, again to the left and right sides of the cell. The bright regions on the very edges are regions of high series resistance caused by the edge cleave being too far away from the front contact grid. This can be easily corrected with more careful processing. The dark regions spreading out from the busbar indicate that the series resistance in these areas increases as you move away from the busbar-the resistance is limited by the line resistance of the fingers. In the centre, the whole area is orange (high resistance-about $6 \Omega \cdot \mathrm{cm}^{2}$ ) which is likely due to poor contact between the $\mathrm{Ni}$ and the $\mathrm{Si}$, creating a high resistance everywhere. The average series resistance of this cell measured from the PL image data is $5.25 \Omega \cdot \mathrm{cm}^{2}$.

Figure 5(a) shows the open-circuit PL image for a cell fabricated using BA-LIP Ni and LIP Cu. The rear point contacts are no longer visible, indicating that the recombination at the contacts is less than it was for the electrolessly Niplated cells.

Figure 5(b) shows the series resistance PL image of the same BA-LIP Ni-plated cell. Due to both the decreased resistive losses at both the front and rear contacts, it was expected that the total $R_{s}$ of bias-assisted LIP Ni cells would be less than the electroless Ni-plated cells, and this is in fact the case. There are fewer bright regions on this sample, with an average series resistance of $2.9 \Omega \cdot \mathrm{cm}^{2}$ being measured using this method (IV measurements indicate $1.48 \Omega \cdot \mathrm{cm}^{2}$ the discrepancy between the measurements may be due to the low shunt resistance affecting the $R_{s}$ calculation from the IV data). Some high resistance is again seen at the edge of the cell, due to the edge cleave again being too distant from the front contact grid. One finger peeled off the front, and this region of slightly higher series resistance is highlighted by the blue circle, but in general this image shows a much more uniform resistance across the surface of the cell. This means that the contact between the $\mathrm{Ni}$ and $\mathrm{Si}$ that is formed through BA-LIP Ni plating is more uniformly good across the surface of the wafer.

3.4. Breakdown Analysis of Series Resistance. Figure 6 depicts the sources of series resistance in a PERC cell. The lateral resistance through the emitter (1), line resistance through the fingers (3), resistance through the base (4), and spreading resistance at the rear contacts (5) are all functions of the material properties and geometry, and as such can be estimated from theory. The contact resistances, at (2) and (6), require measurements to be performed, as the actual resistance at contact locations is often very different to the theoretically expected resistance [23].

Table 4 summarizes the total estimated series resistance contribution based on the theoretical and experimental calculations, as well as the associated power loss from each type of series resistance. The percent power loss was calculated using (2). Effective resistances must be calculated in order to use this equation as, for example, not the full current generated flows through the full sheet resistance. Details on how to calculate the individual effective resistances are provided in the appendix:

$$
\% P_{\text {loss }}=\frac{P_{\text {loss }}}{P_{\text {gen }}}=\frac{I_{\mathrm{MP}}^{2} R_{\text {eff }}}{I_{\mathrm{MP}} V_{\mathrm{MP}}}=\frac{I_{\mathrm{MP}} R_{\mathrm{eff}}}{V_{\mathrm{MP}}} .
$$

As a percentage of total power loss, the rear point contacts are a major contributor to the overall series resistance on the electroless Ni-plated cells. For the cells Ni plated using BA-LIP, the calculated total resistance was within $1 \%$ of that estimated from the $R_{s}$-PL measurements. The value used for the rear contact resistance was that measured for an Al-Si contact after Ni plating; however, the FIB images show that there is also spurious $\mathrm{Cu}$ present at the rear contacts. As the calculated expected resistance is close to that measured, it is assumed that the spurious $\mathrm{Cu}$ did not have a significant impact on the series resistance of the finished devices.

For the cells where the Ni plating was achieved using electroless plating, the calculated total resistance is far greater than the resistance estimated from the IV measurements. 


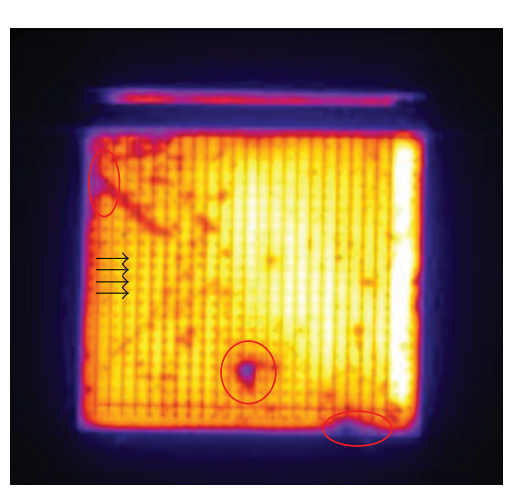

(a)

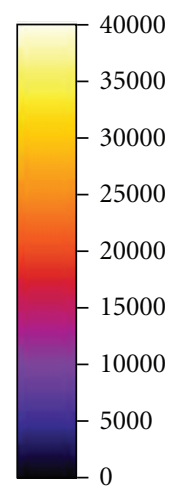

0

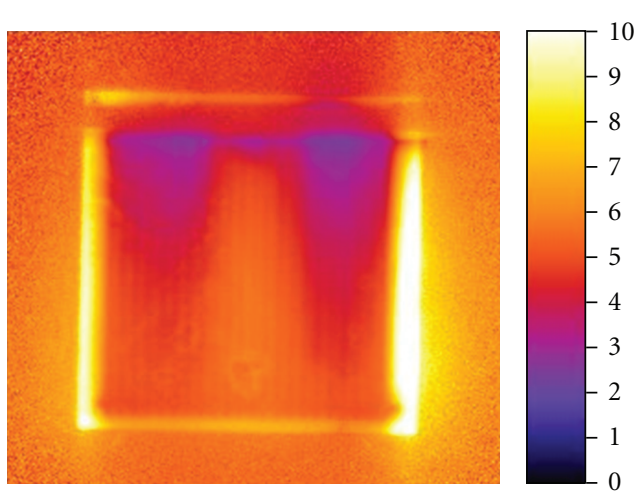

(b)

Figure 4: (a) Open-circuit PL image of a PERC cell made using EN and LIP Cu. The brighter the area, the higher the voltage in that location. The arrows highlight the locations of some of the rear point contacts, red circles are locations of shunts; (b) series resistance PL image of the same cell, bias voltage is $-300 \mathrm{mV}$.

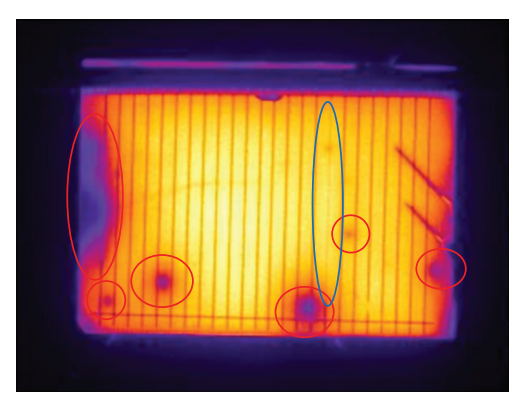

(a)

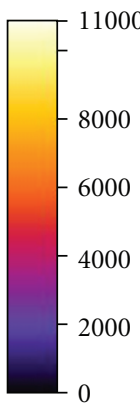

0

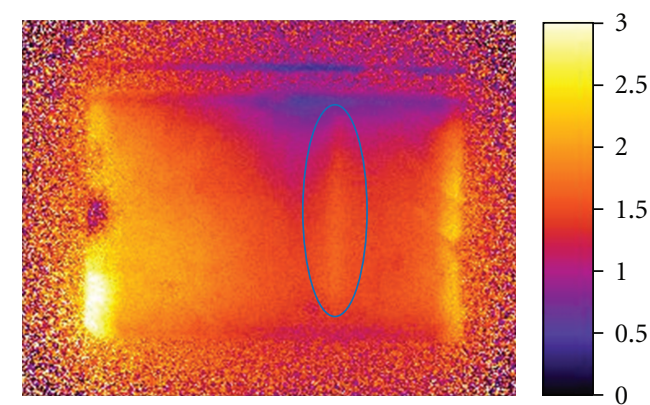

(b)

FIGURE 5: (a) Open-circuit PL image of a PERC cell fabricated using BA-LIP Ni and LIP Cu plating. The edges of the cell have been isolated with a laser. Red circles are shunt locations. Blue circle location of a peeled finger; (b) series resistance PL image of the same cell using a bias voltage of $-300 \mathrm{mV}$.

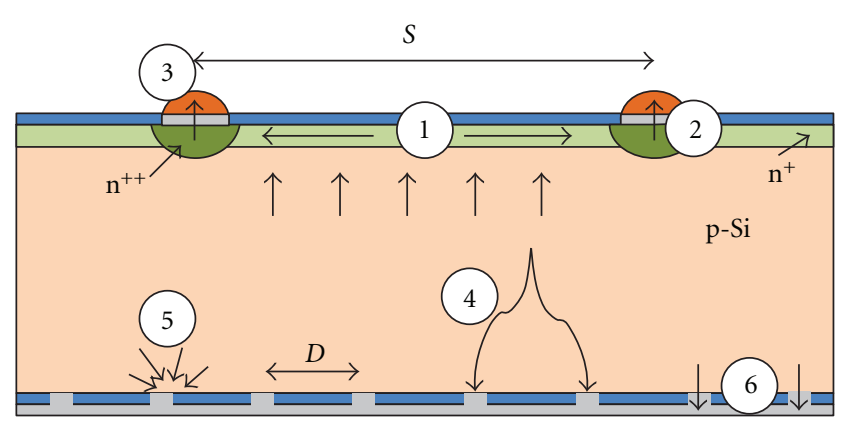

FIGURE 6: Locations of series resistance contributors in a PERC solar cell. $S$ denotes the spacing between the front fingers, and $D$ the spacing between the rear contact points. The length of the fingers is denoted by $L$ (after [23]).

A worst-case scenario was used for the base contact resistance, as the variability in the contact resistance measurements can be great depending on how bad the spurious $\mathrm{Ni}$ on the rear is. Despite using the worst-case experimental values for $\rho_{c}$, the true value could be as low as $0.049 \Omega \cdot \mathrm{cm}^{2}$ contribution, resulting in a percent power loss of $2.5 \%$.
The variation across the electroless plated Ni cells is thought to be due to the variation in the severity of the excess $\mathrm{Ni}$ plating that occurs from cell to cell.

Focused ion beam (FIB) was used to examine the test cell contacts in order to track down a cause of the high resistance in the cells plated using BA-LIP. The rear contacts exhibited some unwanted plating once again, but this time from the LIP Cu. Figure 7 shows a cross-section of a rear contact from a cell plated using bias-assisted LIP.

Light-induced plating is an equivalent technique to electroplating, with the plating voltage being supplied by the cell itself. As such, it was expected that $\mathrm{Cu}$ plating would only occur on the front surface. $\mathrm{Cu}$ plated to the rear, though, again in the locations around the rear point contacts. This is thought to be caused by local areas of relatively different voltage. At the rear surface, the $\mathrm{Al}$ is oxidizing due to electrons being drained to the front of the cell and driving the reduction of $\mathrm{Cu}$ at the front surface. However, the first $\mathrm{Al}$ to oxidize will be the $\mathrm{Al}$ that is in direct contact with the Si surface. The electrons will be taken from there first, and a voltage potential will form between the $\mathrm{Al}$ in contact with the Si and the Al that is floating on the dielectric. The reduction of hydrogen at cathodic sites on the rear surface 
TABLE 4: Sources of series resistance.

\begin{tabular}{|c|c|c|c|c|}
\hline \multirow{2}{*}{ Resistance source } & \multicolumn{2}{|c|}{ Electroless $\mathrm{Ni}$} & \multicolumn{2}{|c|}{ Bias-Assisted LIP Ni } \\
\hline & $R_{s}\left(\Omega \cdot \mathrm{cm}^{2}\right)$ & $P_{\text {loss }}(\%)$ & $R_{s}\left(\Omega \cdot \mathrm{cm}^{2}\right)$ & $P_{\text {loss }}(\%)$ \\
\hline Lateral resistance through the emitter & 0.152 & 0.6 & 0.152 & 0.6 \\
\hline Line resistance along the fingers* & 0.112 & 0.4 & 0.112 & 0.4 \\
\hline Resistance through the base* & 0.072 & 0.3 & 0.072 & 0.3 \\
\hline Spreading resistance** & 0.560 & 2.2 & 0.560 & 2.2 \\
\hline Front contact resistance & 0.090 & 4.6 & 0.107 & 5.5 \\
\hline Rear contact resistance ${ }^{* * *}$ & 0.028 & 28.7 & 0.004 & 4.1 \\
\hline Total & 4.9 & 36.7 & 2.7 & 13.0 \\
\hline Total measured $R$ from IV & 4.1 & & 1.48 & \\
\hline Total measured $R$ from $R_{s}-\mathrm{PL}$ & 5.3 & & 2.9 & \\
\hline
\end{tabular}

* $[14,15]$.

$* *[16,17]$.

$* * *$ From [18].

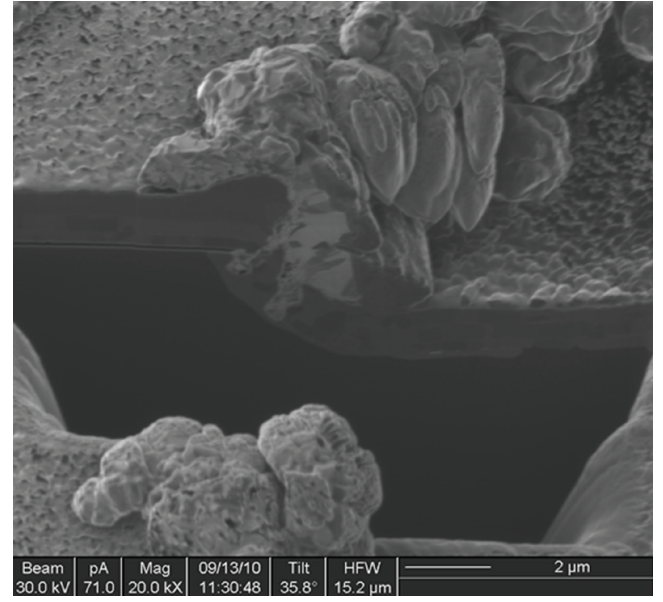

Figure 7: Focused ion beam (FIB) image of the rear of a BA-LIP Ni with LIP Cu test cell. Unwanted Cu plating can be seen at the edges of the rear point contacts.

can result in the formation of bubbles which can cause pitting and variations in surface potential [24]. Bias-assisted LIP of $\mathrm{Cu}$ where the rear surface is not in contact with the plating solution should address these issues. A number of commercial tool manufacturers are now developing BA-LIP tools which keep the Al rear surfaces of cells dry [25].

\section{Summary and Future Research}

In order to achieve higher-efficiency solar cells at lower cost, new fabrication methods such as inkjet patterning and metal plating may need to be considered. This research has identified and quantified the major series resistance losses inherent in the IJP PERC cell. The rear contact resistance of the Al-Si contacts is higher than expected for cells that were Ni plated using both electroless plating and BA-LIP. This results in higher series resistance and lower fill factors being achieved than is desirable. The specific contact resistivity of the these rear contacts in the electroless Ni-plated cells was an order of magnitude greater than for the cell plated using
BA-LIP due to spurious plating of $\mathrm{Ni}$ in the regions of the rear contacts.

Future work should focus on methods of achieving low resistance contacts on the rear of the cell. Bias-assisted LIP tools which maintain the rear surface dry will be required to ensure that plated metals do not interfere the electrical properties of the rear contacts. In addition to the rear contact resistance, the rear spreading resistance also needs to be reduced. Ideally this would be achieved by spacing the contacts closer together; however, unless the contact regions are heavily doped to minimize the minority carrier concentration at the surface, the recombination in the device will be increased resulting in a lower device voltage. Future work can also focus on how to form doped rear contact regions, either through laser-fired contacts [2], laser doping $[1,3]$, or local $\mathrm{Al} \mathrm{BSF}$ formed by firing $\mathrm{Al}$ through openings in a rear passivation layer.

\section{Appendix}

The locations where series resistance occurs in the cell are shown in Figure 5. In this section, the calculations done for determining each portion of the series resistance are shown.

(A) Lateral Resistance through the Emitter. When calculating the series resistance as a result of the current flowing through the emitter, it is important to note that not all the current will see the full resistance; the current generated close to the contact fingers will have less distance to travel through the emitter and experience less resistance than current generated midway between two fingers. A proper summation of the current must be done in order to obtain the effective resistance contribution from the emitter. From $[14,15]$, the following equation can be used to determine the resistance contribution from the emitter:

$$
R_{\text {eff }}=\frac{1}{3} \frac{S / 2}{L} \frac{\rho}{t}
$$

where $S$ is the finger spacing, $L$ is the length of the fingers, and $\rho / t$ is the sheet resistance of the emitter. With an emitter sheet resistance of $\sim 120 \Omega$ /sq, the effective resistance 
contribution of the emitter is calculated to be $0.019 \Omega$. As the dimensions on all the test cells are the same, this is the expected contribution on all the wafers.

(B) Line Resistance along the Fingers. As with the emitter, not all the current flows through the full length of the fingers; the current generated close to the busbar will have less distance to travel through the metal than the current generated on the far side of the cell. As such, the geometry of the problem is the same, and the same equation that was used to calculate the effective series resistance for the emitter can be used for the fingers. In this case,

$$
R_{\mathrm{eff}}=\frac{1}{3} \frac{L}{W} \frac{\rho}{t},
$$

where $L$ is again the length of the fingers, $W$ is the width of the fingers, $\rho$ is the specific resistivity of the $\mathrm{Cu}$, and $t$ is the thickness of the $\mathrm{Cu}$. From the dimensions and the resistivity of $\mathrm{Cu}$ being $16.78 \mathrm{n} \Omega \cdot \mathrm{m}$, the effective resistance from the front fingers works out to be $0.014 \Omega$.

(C) Resistance through the Base. The resistance contribution from the base can be calculated from:

$$
R_{b}=\rho_{b} D
$$

where $\rho_{b}$ is the resistivity of the base and $D$ is the spacing between the rear contacts [16]. From the geometry and a base resistivity of $0.5 \Omega \cdot \mathrm{cm}$, the resistance through the base material is $0.075 \Omega \cdot \mathrm{cm}^{2}$, and a total resistance contribution of $9.4 \mathrm{~m} \Omega$.

(D) Spreading Resistance at the Rear Contacts. The spreading resistance at the base point contacts can be calculated from the geometry and the material properties of Si from:

$$
R_{\mathrm{sp}}=D^{2} \frac{\rho_{b}}{2 d_{c}},
$$

where $\rho_{b}$ is the resistivity of the base, $D$ is the spacing of the rear contacts, and $d_{c}$ is the diameter of the rear contact [ 15 , 16]. From the geometry and a base resistivity of $0.5 \Omega \cdot \mathrm{cm}$, the spreading resistance at the rear contacts works out to be $0.56 \Omega \cdot \mathrm{cm}^{2}$, and a total resistance of $0.07 \Omega$.

(E) Contact Resistance. Contact resistance between the metal contacts and the Si was determined from TLM test structures, the details of which were given in Sections 3.1 and 3.4.

\section{Acknowledgment}

M. A. T. Lenio thanks John Durrant, Alex Han, and Kalai Valliappan for their assistance with the processing and imaging of the test samples used in this research. She would also like to thank Scott McDaid for his help in making the BA-LIP setup, and the UNSW SunSwift Solar Racing Team for the use of their machine shop.

\section{References}

[1] Suntech Power Co. Ltd., http://www.suntech-power.com/.

[2] E. Schneiderlochner, R. Preu, R. Ldemann, and S. W. Glunz, "Laser-fired rear contacts for crystalline silicon solar cells," Progress in Photovoltaics: Research and Applications, vol. 10, no. 1, pp. 29-34, 2002.

[3] B. S. Tjahjono, L. Mai, Z. Hameiri et al., "High efficiency solar cell structures through the use of laser doping," in Proceedings of the 22nd European Photovoltaic Solar Energy Conference, pp. 966-969, Milan, Italy, 2007.

[4] R. Y. Utama, A. J. Lennon, M. A. Lenio et al., "Inkjet printing for high efficiency selective emitter silicon solar cells," in Proceedings of the 22nd European Photovoltaic Solar Energy Conference, pp. 1687-1690, Valencia, Spain, 2008.

[5] A. J. Lennon, R. Y. Utama, M. A. T. Lenio, A. W. Y. Ho-Baillie, N. B. Kuepper, and S. R. Wenham, "Forming openings to semiconductor layers of silicon solar cells by inkjet printing," Solar Energy Materials and Solar Cells, vol. 92, no. 11, pp. 1410-1415, 2008.

[6] T. Bruton, N. Mason, S. Roberts et al., "Towards 20\% efficient silicon solar cells manufactured at 60 MWp per annum," in Proceddings of the 3rd World Conference on Photovoltaic Energy Conversion, pp. 899-902, Osaka, Japan, May 2003.

[7] A. Wang, High efficiency PERC and PERL silicon solar cells [Ph.D. thesis], Department of Electrical Engineering, University of New South Wales, Sydney, Australia, 1992.

[8] M. Lenio, J. Howard, F. Jentschke, A. Lennon, and S. Wenham, "Design, fabrication and analysis of high efficiency inkjet printed passivated emitter rear contacted solar cells," in Proceedings of the 37th IEEE Photovoltaic Specialists Conferenc (PVSC'11), Seattle, Wash, USA, 2011.

[9] M. Aleman, N. Bay, M. Fabritius, and S. Glunz, "Characterization of electroless nickel plating on silicon solar cells for the front side metallization," in Proceedings of the 22nd European Photovoltaic Solar Energy Conference, pp. 1590-1592, Milan, Italy, 2007.

[10] D. Pysch, A. Mette, and S. W. Glunz, "A review and comparison of different methods to determine the series resistance of solar cells," Solar Energy Materials and Solar Cells, vol. 91, no. 18, pp. 1698-1706, 2007.

[11] T. Trupke, E. Pink, R. A. Bardos, and M. D. Abbott, "Spatially resolved series resistance of silicon solar cells obtained from luminescence imaging," Applied Physics Letters, vol. 90, no. 9, Article ID 093506, 3 pages, 2007.

[12] H. Kampwerth, T. Trupke, J. W. Weber, and Y. Augarten, "Advanced luminescence based effective series resistance imaging of silicon solar cells," Applied Physics Letters, vol. 93, no. 20, Article ID 202102, 3 pages, 2008.

[13] Transene Company Inc., http://www.transene.com/.

[14] N. C. Wyeth, "Sheet resistance component of series resistance in a solar cell as a function of grid geometry," Solid State Electronics, vol. 20, no. 7, pp. 629-634, 1977.

[15] L. D. Nielsen, "Distributed series resistance effects in solar cells," IEEE Transactions on Electron Devices, vol. 29, no. 5, pp. 821-827, 1982.

[16] J. Zhao, A. Wang, and M. A. Green, "Series resistance caused by the localized rear contact in high efficiency silicon solar cells," Solar Energy Materials and Solar Cells, vol. 32, no. 1, pp. 89-94, 1994.

[17] B. Gelmont and M. Shur, "Spreading resistance of a round ohmic contact," Solid-State Electronics, vol. 36, no. 2, pp. 143146, 1993. 
[18] M. A. T. Lenio, A. J. Lennon, A. Ho-Baillie, and S. R. Wenham, "Effect of electroless nickel on the series resistance of highefficiency inkjet printed passivated emitter rear contacted solar cells," Solar Energy Materials and Solar Cells, vol. 94, no. 12, pp. 2102-2107, 2010.

[19] E. J. Lee, D. S. Kim, and S. H. Lee, "Ni/Cu metallization for low-cost high-efficiency PERC cells," Solar Energy Materials and Solar Cells, vol. 74, no. 1-4, pp. 65-70, 2002.

[20] S. Sze and K. K. Ng, Physics of Semiconductor Devices, John Wiley \& Sons, New Jersey, NJ, USA, 3rd edition, 2007.

[21] K. K. Ng and R. Liu, "On the calculation of specific contact resistivity on <100> silicon," IEEE Transactions on Electron Devices, vol. 37, pp. 1535-1537, 1990.

[22] P. Wurfel, Physics of Solar Cells, vol. 1, Wiley-VCH, Weinheim, Germany, 2005.

[23] A. Milne, The passivated emitter and rear solar cell [Ph.D. thesis], Department of Electrical Engineering, University of New South Wales, Sydney, Australia, 1991.

[24] G. A. DiBari, "Nickel plating," Metal Finishing, vol. 93, no. 1, pp. 259-279, 1995.

[25] Technic Inc., "SEMCON semiconductor plating tools," http:// www.technic.com/. 

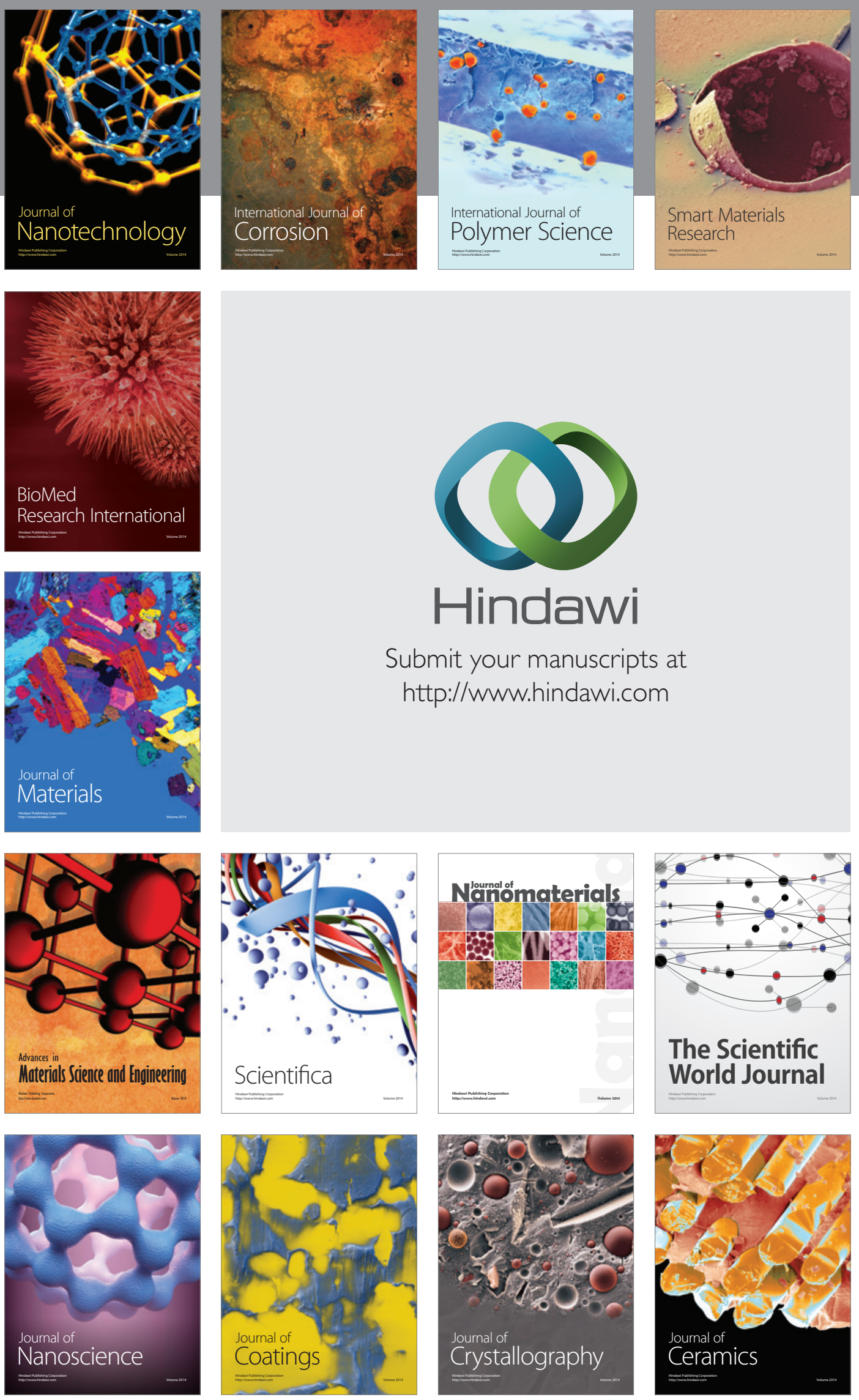

The Scientific World Journal

Submit your manuscripts at

http://www.hindawi.com

\section{World Journal}

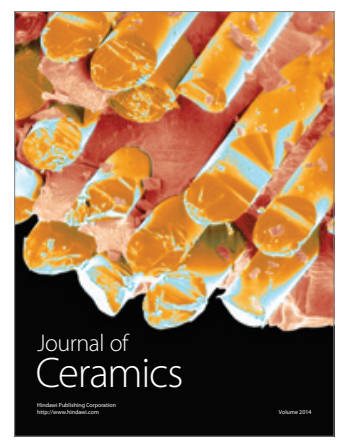

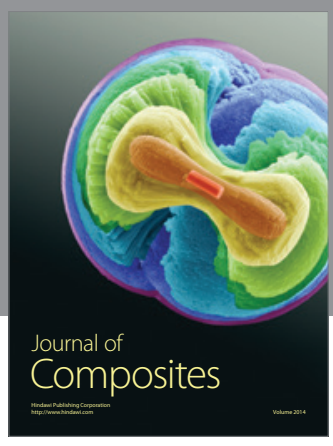
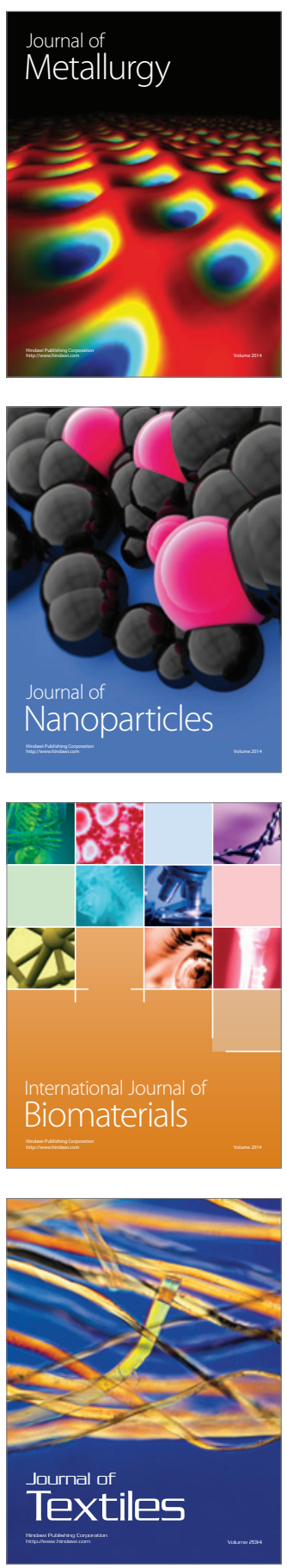